
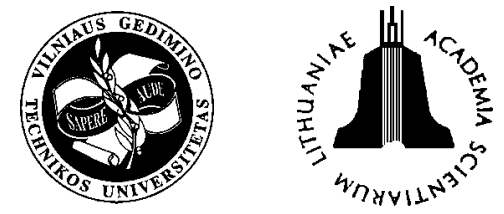

JOURNAL OF CIVIL ENGINEERING AND MANAGEMENT

http:/www.vtu.lt/english/editions

2004, Vol X, No 1, 77-85

\title{
MULTIPLE CRITERIA DECISION SUPPORT WEB-BASED SYSTEM FOR BUILDING REFURBISHMENT
}

\author{
Edmundas Kazimieras Zavadskas, Artūras Kaklauskas, Andrius Gulbinas \\ Vilnius Gediminas Technical University, Sauletekio al. 11, LT-10223 Vilnius-40, Lithuania. \\ E-mail: Edmundas.Zavadskas@adm.vtu.lt
}

Received 5 Jan 2004; accepted 23 Feb 2004

\begin{abstract}
In order to design and realise an efficient building refurbishment, it is necessary to carry out an exhaustive investigation of all solutions that form it, ie planimetric and volumetric changes, the elimination of building deterioration and obsolescence, the improvement of architectural and aesthetic appearance and indoor environmental quality, etc). The efficiency level of the considered building's refurbishment depends on many factors, including cost of refurbishment, annual fuel economy after refurbishment, tentative pay-back time, harm to health of the materials used, aesthetics, maintenance properties, functionality, comfort, sound insulation and longevity, etc. Solutions of an alternative character allow for a more rational and realistic assessment of economic, ecological, legislative, climatic, social and political conditions, traditions and for better satisfaction of architectural, comfort, functional, maintenance and other customer's requirements. They also enable one to cut down on refurbishment costs. The selection of a refurbishment version mostly depends on the needs and existing financial capability of tenants. Based on an analysis of the existing neural networks, information, expert and decision support systems and in order to determine the most efficient versions of building refurbishment, a Multiple Criteria Decision Support Web-Based System for Building Refurbishment (BR-DSS) consisting of a database, database management system, model-base, model-base management system and a user interface was developed. The developed BR-DSS and its practical application are described in the paper. Basing oneself on the developed system and database, it is possible to perform the alternative design of a building's refurbishment, multiple criteria analysis and make the selection of the most efficient versions, etc.
\end{abstract}

Keywords: refurbishment, alternative design, web-based decision support system, multiple criteria analysis.

\section{Factors affecting the efficiency of refurbishment decisions and the determination of rational alternatives}

Refurbishment decisions are influenced by many microlevel factors (deterioration and obsolescence of a building, indoor environmental quality, technological, technical, the lower fuel bills for householders, health benefits (reduced cold and damp-related illness)) and by macrolevel factors (environmental (a less polluted environment, the saving of limited nature resources), social (increasing social equity, improving human health) as well as economic factors (increasing employment, the creation of wealth) benefits).

As an example, further on we shall briefly discuss some of the above-mentioned microlevel efficiency level factors. In B.L.P. Peuportier's opinion (2001), building comfort is defined by a given set point temperature (possibly varying in time), for heating and, if needed, for air conditioning and by sufficient illumination, ventilation and noise protection.

According to D. Caccavelli et al (2002), the following criteria of functional obsolescence are considered: user's needs (eg compliance with user's professional activities in office space), flexibility (ie capacity to easily modify the interior space partitioning and the general office layout without any major intervention in building installations and structure), divisibility (ie capacity to divide the building into separate and independent zones), maintainability (ie capacity to facilitate easy maintenance of the premises) and compliance with regulations, ie capacity of the various installations to comply with national regulations).

In P. M. Bluyssen's opinion (2000), problems with the indoor environment quality were defined to be basically originating from seven issues, namely: humidity (dry/dusty air, problems with eyes, allergy), noise (annoyance, too high sound level, privacy, poor control of noise), thermal comfort (too cold, too warm, draught, temperature differences, no control), air quality and ventilation (smell, irritation to eyes, throat and headaches), lighting (too much/little light), safety (feeling of insecurity) and apartment utilities (unacceptable quality of water supply, unacceptable quality of heating or cooling utilities, unacceptable quality of shutters or sunshades). 
The total boiler efficiency depends on the quality, the size, the adjustment, the control and the maintenance of the burner-boiler combination (F. J. Rey and E. Velasco, 2000).

According to C. A. Roulet (2001), users usually try avoid dangerous or damageable materials such as those containing CFC's or other halogenated compounds, formaldehyde, heavy metals, toxic organic solvents, etc.

Various quantitative and qualitative factors influence decision-making as well. Recently, high-energy consumption has taken on not only economic, but also ecological $\left(\mathrm{CO}_{2}\right.$ emissions) and social importance. In the future, external costs of the environment will be included in the price of energy and therefore energy efficient buildings will be very important (V. Butala et al, 1999). Since, an energy efficiency-upgrading programme can provide local employment, offer training opportunities, and redirect resources into a local community it can be linked into wider social and economic regeneration programmes (C. Goodacre et al, 2002).

The problem is how to define an efficient building refurbishment process when many various parties are involved and the alternative versions come to number in the thousands. Moreover, the realisation of some objectives seems more rational from the economic perspective though from other perspectives (ie ecological, indoor environmental quality, social, etc) they have other significances.

By way of an illustration, we provide a few examples for the determination of rational alternatives.

G. Carrilho da Graça et al (2002) present a performance evaluation of two passive cooling strategies, daytime ventilation and night cooling, for a generic, six-story suburban apartment building in Beijing and Shanghai. This investigation uses a coupled, transient simulation approach to model heat transfer and airflow in the apartments. R. Becker et al (2002) compare effects on thermal performance and energy use of various pre-cooling and ventilation strategies, which might be used for reducing peak power demands in typical office buildings that are located in moderately warm climatic regions. V. Kukadia et al (1998) report the findings of a pilot field study that was carried out over a one-week period in winter 1996 to investigate the internal and external air pollution levels of two adjacent buildings, one naturally ventilated and the other air-conditioned in an urban area, to investigate their relative attenuation of external pollution levels and to compare internal levels with the existing air quality guidelines. The radiant ceiling panel system and conventional air-conditioning systems have been compared both experimentally and numerically in terms of thermal comfort, energy consumption and cost efficiency (T. Imanari et al, 1999). By applying the numerical simulation programme named TRNSYS, the energy costs of a VAV system and a cooling ceiling system have been compared (F. Sodec, 1999).

A geographical information system's basic technique was used to estimate the heat discharge distribution all over Tokyo. The improvements in the urban thermal environment via various measures were analysed for two types of scenarios, namely, scenarios related to the management of heat discharge sources and those with urban surface modifications (S. Dhakal et al, 2002).

D. Kolokotsa et al (2001) present and evaluates control strategies for adjustment and preservation of air quality, thermal and visual comfort of a building's occupants while, simultaneously, energy consumption reduction is achieved. The objectives of the proposed control strategy are: satisfaction of the users' preferences for thermal comfort, visual comfort and indoor air quality, simultaneously; optimum response of the controlled variables, avoiding over-shootings and oscillations that can cause energy waste; monitoring the energy consumption for heating/cooling and electric lighting (D. Kolokotsa et al, 2001).

\section{Decision-making models and methods}

A thorough building's refurbishment evaluation is quite difficult to undertake, because a building and its environment are complex system (technical, technological, ecological, social, comfort, esthetical, etc), where all sub-systems influence the total efficiency performance and where the interdependence between sub-systems play a significant role.

Many decision-making models and methods (costbenefit analysis (C. Goodacre et al, 2002), multiple criteria analysis (E. Brandt et al, 2002), the lattice method for global optimisation (A. Saporito et al, 2001), predicted a building's habitability index (T. Kusuda, 2001) and energy rating systems for existing houses (R.Zmeureanu et al, 1999), etc.) have been developed in the world for solving the above and other problems.

C. Goodacre et al (2002) uses a cost-benefit analysis framework to assess the potential scale of some of the benefits from the comprehensive upgrading of heating and hot water energy's efficiency in the English building stock. C. Goodacre et al (2002) attempted to evaluate the potential scale for societal costs that are associated with poor levels of domestic space heating and hot water energy efficiency in the English building sector. The basic premise of this paper has been that an appraisal of these costs should be evaluated against a wider range of potential benefits, not just the direct benefits (micro-economic) current government monetary appraisals (Goodacre et al, 2002).

The TOBUS method aims at offering a tool to select office building's upgrading solutions with respect to multiple criteria. One of the key elements to reach this goal is an assessment of the degree of physical degradation, extent of any degradation, extent of the necessary works to renovate the building and the costs (E. Brandt et al, 2002).

The energy performance in buildings is a complex function of the building's form and structure, heating system, occupancy pattern, operating schedules, and the 
climatic conditions. To carry out a multi-parameter analysis for the optimisation of the building's energy performance, the lattice method for global optimization was used (A. Saporito et al, 2001).

T. Kusuda (2001) would like to see the extension of the predicted building habitability index (PIHI) as an integrated evaluation criterion for a building's performance in which the simulated hourly energy consumption, comfort index and system economic factors were weighted (in accordance with specific application requirements) and algebraically summed up to arrive at an index for determining the building's air conditioning needs. This PIHI concept can be extended to include other elements such as lighting, acoustics, moisture condensation, plumbing, etc (T. Kusuda, 2001).

According to R. Zmeureanu et al, (1999), different approaches have been developed to evaluate the energy performance of houses, using a simple index, and they are known under the generic term of Home Energy Rating Systems (HERS) which can be classified in the following three main categories: the points system, which evaluates the energy performance of a house by giving points of performance or scores to each sub-system such as exterior walls, roof or heating system; the performance system, which assigns an index of performance in terms of the annual heating energy consumption or cost; and the awareness system, which recommends the annual total and heating site's energy consumption, and the corresponding costs, in terms of the year the house was constructed and its climatic zone and the source of energy.

\section{Analysis of building refurbishment automation applications}

The major players in a building's refurbishment can use calculators, analysers, software, neural networks, expert and decision support systems, etc.

A calculator is software application used for completing mathematical calculations. Calculators range from very cheap software, capable of performing basic arithmetical operations, to those whose capabilities extend to sophisticated mathematical and statistical manipulations and those that may be programmed with a large number of steps. Web sites sometimes contain refurbishment calculators: Comfort calculator [1] (analyses thermal comfort and estimates the optimal temperature), Lighting calculator [2] (identifies and analyses options for reducing lighting costs), Ventilation calculator [3] (examines the supply of outside air ventilation to a space) and Home Improvement Calculators [4], etc.

Interested parties also use software with various purposes as listed below:

- Whole-building analysis (energy simulation, load calculation, renewable energy, retrofit analysis and sustainability/green buildings) [9];

- Codes and standards [19];

- Materials, components, equipment, and systems (envelope systems, HVAC equipment and systems and lighting systems) [20];

- Other applications (atmospheric pollution, energy economics, indoor air quality, multi-building facilities, solar/climate analysis, training, utility evaluation, validation tools, ventilation/airflow and water conservation) [21].

For example, different retrofit purpose software BLAST [10], DOE-2 [11], EA-QUIP [12], EZ Sim [13], EZDOE [14], FEDS [15], SERIRES [16], tsbi3 [17], VisualDOE [18]) can help analyse various retrofit situations.

D. B. Crawley et al (2001) describe a comparison of major features and the capabilities of different simulation software (EnergyPlus, BLAST, IBLAST, and DOE2): general features (integrated, simultaneous solution, reporting mechanism, e g standard reports, user-definable reports, visual surface reports, etc), load calculation features (heat balance calculation, moisture absorption/desorption, thermal comfort, etc), and HVAC features (atmospheric pollution calculation and calculate reductions in greenhouse gases, etc).

The major players in a building's refurbishment can use various purpose decision-support systems. The decision-support system (DSS) provides a framework through which decision-makers can obtain the necessary assistance needed for making decisions through an easy-touse menu or command system. Generally, a DSS will provide help in formulating alternatives, accessing data, developing models and interpreting their results and by selecting options or analysing the impacts of a selection.

The special issue of "Energy and buildings" (Vol 31 , Issue 2, Febr 2000) was prepared by the developers of EPIQR (Energy Performance Indoor Environmental Quality Retrofit) and is in use today. EPIQR is a methodology that was developed to assist apartment building owners who are considering the refurbishment or retrofitting (upgrading) their building stock (M. Jaggs, et al 2000). EPIQR is a decision tool that combines financial, technical, energy, and comfort analysis (J. L. Genreet al, 2000). EPIQR has been developed to act as an assisting tool for surveyors, architects or building owners to select the most suitable refurbishment actions for an apartment block by enabling them to upgrade the physical and functional state of the building, to improve indoor conditions for tenants and to reduce the energy consumption (D. Caccavelli et al, 2000).

The special issue "Energy and Buildings" (Vol 34, Issue 2, Febr 2002) is a collection of nine contributions prepared by the developers of TOBUS (a new European diagnosis and decision-making method and software for office building refurbishment). The papers provide an overview of the TOBUS methodology, modules and multimedia software, the assessment procedures used for the diagnosis of a building's degradation state, the implemented approaches and specific module characteristics for an evaluation of its functional obsolescence, provide 
an assessment of the potential energy and natural resources conservation, include an evaluation of the indoor environmental quality and the results from the test's surveys implemented in 15 European office buildings as well as the use of infrared thermography as an optional tool for assisting building diagnostics, a multicriteria analysis and a constructive approach that helps an expert in designing retrofit scenarios and a more detailed description of the new TOBUS software and its features (C. A. Balaras, 2002).

Following in the footsteps of EPIQR and TOBUS, "a decision-making tool for long-term efficient investment strategies in building maintenance and refurbishment - INVESTIMMO" is currently under development in the framework of a European research programme as well as technological development and demonstration on Competitive and Sustainable Growth and was coordinated by CSTB in France (C. A. Balaras, 2002).

Expert systems today generally serve to relieve a 'human' professional of some of the difficult but clearly formulated tasks. For example, S. Mazouz et al (2001) have presented a description and analysis of various expert systems in architectural design for such purposes.

Neural network is a method of computing that tries to copy the way the human brain works. A group of processing elements receives data and at the same time links are made between the elements, as the repeated patterns are recognised (Oxford, 1996). Many various-purpose neural networks can be used for refurbishment. Recent research in building and related artificial intelligence topics have shown that "smart control techniques" such as fuzzy systems and neural networks can contribute to the reduction of energy consumption while maintaining indoor comfort in acceptable margins (D. Kolokotsa et al, 2001). T. T. Chow et al (2002) introduces a new concept of integrating neural network $(\mathrm{NN})$ and genetic algorithm (GA) in the optimal control of an absorption chiller system. Based on a commercial absorption unit, neural network was used to model the system's characteristics and the genetic algorithm as a global optimisation tool.

Many questions are raised during the integration of building refurbishment automation systems. In $\mathrm{T}$. Kusuda's opinion (2001), the integrated system should be capable of representing and analysing details in as much as the user wants to pursue his/her purpose. With this programme, one can determine the cause of unwanted moisture condensation, noise, odour, glare, malfunction of the mechanical and electrical, plumbing systems ( $\mathrm{T}$. Kusuda, 2001). According to V. Dorer and A. Weber (1999), only a few computer programmes allow for the comfort-integrated evaluation (ie air quality, thermal, visual and acoustic comfort).

The above calculators, software, neural networks, decision support and expert systems, etc, are not connected. Therefore, in the future the above building refurbishment automation solutions to some extent have to be integrated.

\section{A multiple criteria decision support web-based sys- tem for building refurbishment}

Based on an analysis of the existing neural networks, information, expert and decision-support systems and in order to determine the most efficient versions of building refurbishment, a Multiple Criteria Decision- Support Web-Based System for Building Refurbishment (BRDSS) consisting of a database, database management system, model-base, model-base management system and a user interface was developed.

The BR-DSS allows users to: present information of the general physical and functional state of the building; present information of the physical state of the building's envelope; calculate the volume of work to be carried out; rationalise the energy consumption of the building; propose the required measures to increase the quality of air and indoor environment and analyse the refurbishment scenarios by taking into account the system of criteria, etc.

\subsection{Database}

Building refurbishment involves a number of interested parties (ie clients, users, designers, contractors, suppliers, facilities management organisations, local authorities, government and its institutions, etc) who pursue various goals and have different potentialities, educational levels and experiences. This leads to various approaches of the above parties to decision-making in this field. In order to do a full analysis of the available alternatives and to obtain an efficient compromise solution, it is often necessary to define the differences on the basis of economic, ecological, indoor environmental quality (humidity, noise, thermal comfort, air quality (and ventilation), lighting, safety and security, apartment utilities), legal, social, technical, technological and other type of information. This information should be provided in a user-oriented way.

Economic information on building refurbishment includes the building and plot costs, maintenance costs, insurance, taxes and interest rates (in case of crediting), etc. This information may be described in minor detail. The crediting of refurbishing may be provided by various sources. Therefore, some additional information on alternative crediting sources and terms might be quite helpful for decision- makers.

Technical building characteristics include the total and usable building area, the number and dimensions of rooms, technical characteristics of utilities and the like.

The apartments of a building may be private, stateowned or rented. This legal factor also determines whether the inhabitants are interested in refurbishing of a building or not.

At present, some Lithuanian inhabitants of the lowincome group (ie pensioners, unemployed and large families) cannot afford the payment of bills for heating their premises. The thermal renovation of a building would 
reduce heating costs and save state expenditures on social allowances. In addition, the political party in power that cannot solve this urgent problem in a rational way will not be elected in the coming elections. Thus, the problem appears to be not only a social one but also a political one.

In a similar way, it is possible to demonstrate the need to have other information (eg data on building comfort and aesthetics, etc) that is related to the complex efficiency of the analysed alternative versions of a building refurbishment.

The presentation of information needed for decisionmaking in the BR-DSS may be in a conceptual form (digital/numerical, textual, graphical, diagrams, graphs and drawing, etc), photographic, sound, visual (video)) and quantitative forms. Therefore the presentation of quantitative information involves criteria systems and subsystems, units of measurement, values and initial weight that fully define the provided variants. Conceptual information means a conceptual description of the alternative solutions, the criteria and ways of determining their values and the weight, etc.

In this way, the BR-DSS enables the decision-maker to receive various conceptual and quantitative information on building refurbishment from a database and a model-base allowing him/her to analyse the above factors and to make an efficient solution.

The analysis of database structures in decision support systems according to the type of problem solved reveals their various utilities. There are three basic types of database structures: hierarchical, network and relational. BR-DSS has a relational database structure when the information is stored in the form of tables. These tables contain quantitative and conceptual information.
Each table is given a name and is saved in the computer's external memory as a separate file. Logically linked parts of the table form a relational model. The following tables form the BR-DSS's database:

- Initial data tables. These contain general facts about the building considered and the information of its deterioration and obsolescence. The reasons for refurbishing and their significance as well as the money to be spent on it are also included.

- Tables assessing refurbishment solutions [walls (see Table 1), windows, roof, floors, volumetric planning and engineering services, etc]. These contain quantitative and conceptual information about alternative building refurbishment solutions relating to a building's enclosures, utilities and space planning, etc.

- Tables of multi-variant design. These provide quantitative and conceptual information on the interconnection of the elements to be renovated, their compatibility and the possible combinations as well as data on the complex multi-variant design of a building refurbishment.

The collection, processing and presentation of information for database in an acceptable form are a complicated and time-consuming process. The information collected in a database should be reliable, fully describing a building refurbishment and enable the BR-DSS to perform an efficient multi-variant refurbishment design and multiple criteria analysis.

To design the structure of a database and perform its completion, storage, editing, navigation, searching and browsing, etc a database management system was used in this research.

Table 1. The initial data for multiple criteria analysis of thermal renovation of walls

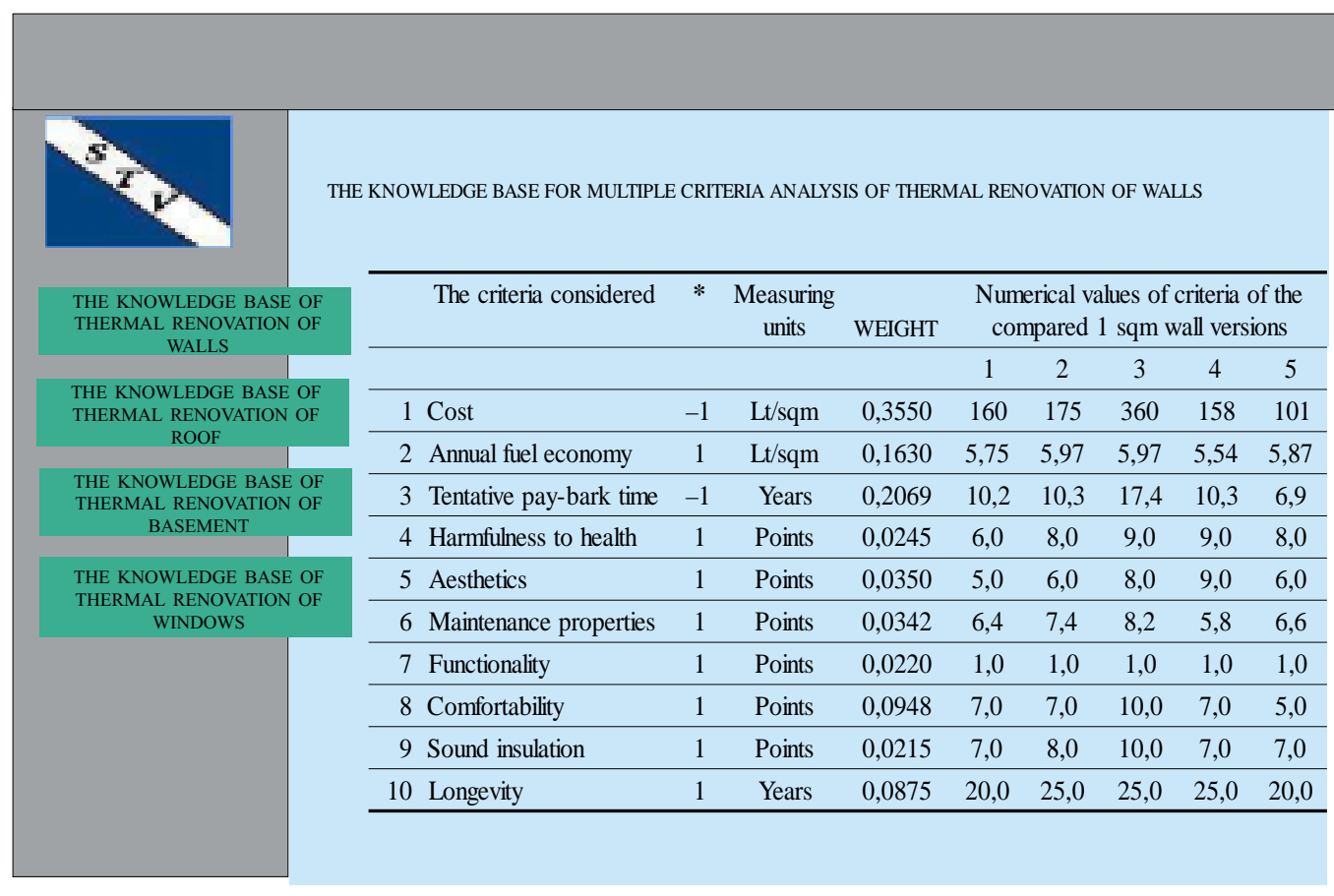


Tables of initial data contain the following information:

- General facts about the building to be analysed;

- Results of diagnosis and questionnaires (data on the deterioration and obsolescence of a building, etc);

- Top priority and significance of the building refurbishment objectives;

- The amount of money intended for refurbishment.

The user seeking for an efficient refurbishment of a building should provide in tables of the initial data the exact information about a building's deterioration and obsolescence, refurbishing aims and significance as well as the client's financial situation. It should be noted that various clients making refurbishment design variants and a multiple criteria analysis of the same building often get diverse results. This may be due to the diversity of the overall aims and financial positions of the clients. Therefore the initial data provided by clients for calculating the refurbishment project differ and consequently lead to different final results.

The tables of refurbishing variant assessments contain the evaluation data on building refurbishment and referring to:

- Specific elements of a building including:

- The fixing of balconies, canopies and cornices;

- The sealing of a building's joints and external walls;

- Thermal renovation of walls, windows, roofs, etc;

- Engineering services (water supply, sewerage, heating system, etc).

- Structural-spatial changes.

The tables of refurbishing variant assessments contain the variants available and their quantitative and conceptual description. The process of drawing up the tables of refurbishing variant assessments consists of the following steps:

- Collection and presentation of general information about the variants under consideration,

- Establishment and conceptual description of the systems and subsystems according to the criteria,

- Choosing the units of measurement,

- Estimation of the criteria values with a description of the calculation process and its presentation,

- Determination of the initial weight of the criteria with a description of the calculation process and its presentation.

The information applied for compiling the tables of refurbishing variant assessments is based on: the use of diagnosis, questionnaires, building cost indices by referring to the costs incurred by contractors (labour, materials, plant and overheads (excluding profits)); tender price indices which reflect the cost to the client (bills of quantities from successful tenders, unit prices as published in builders' price books or trade journals (includes overheads and profits); various statistical methods, analysed projects and recommendations, etc.

The owner and the occupants of a building being refurbished have their specific needs and financial situation. Therefore every time when using the BR-DSS they may make corrections of the database according to their aims and their financial situation. For example, a certain client considers the sound insulation of the external walls to be more important than their appearance while another client is quite of the opposite opinion. The client striving to express his/her attitude towards these issues numerically may ascribe various significance values to them that eventually will affect the general estimation of a project. Though this assessment may seem biased and even quite subjective, the solution finally made may exactly meet the client's requirements, aims and affordability.

Uniform types of relational tables have been chosen to facilitate the entering of appropriate data into the database. Such a unified database also makes it possible to easily correct and introduce new information as well as efficiently carrying out the computation.

The above tables are used as a basis for working out the matrices of decision-making. These matrices, along with the use of a model-base and models, make it possible to perform a multi-variant design and a multiple criteria evaluation of alternative building refurbishing projects, resulting in the selection of the most beneficial variants.

In order to design and realise an effective building refurbishment project the alternatives available should be analysed. A computer-aided multi-variant design requires the availability of the tables containing the data on the interconnection of the elements to be renovated and the solutions made. It also requires their compatibility, possible combination and the multi-variant design.

Since the objectives and financial situations of the BR-DSS users often vary the initial design data then consequently the results obtained will also be different. Therefore the objectives and the client's financial situation are expressed quantitatively and provided as the initial data for calculations. These data should be related to the other information in the tables. Based on the above tables of a multi-variant building design, the possible refurbishment variants are then developed. When using the method of a multi-variant design as suggested by the authors [5-8] up to 100,000 alternative building refurbishment projects may be obtained. These project versions are checked for their capacity to meet the various requirements. Those that do not satisfy these requirements are excluded from any further consideration. In designing a number of variants of building refurbishment the problem of weight compatibility of the criteria also arises. In this case, when a complex evaluation of the alternatives is carried out, the value of the criteria's weight is dependent on the overall criteria being assessed as well as on their values and the initial weight.

\subsection{Model-base}

The efficiency of a building refurbishment variant is often determined by taking into many factors. These factors include an account of the economic, aesthetic, 
technical, comfort, legal, social and other factors. The model-base of a decision support system should include models that enable a decision-maker to do a comprehensive analysis of the available variants and to make a proper choice.

The more alternative versions that are investigated before making a final decision, the greater the possibility to achieve a more rational end result. Basing oneself on the collected information and the BR-DSS, it is possible to perform a multiple criteria analysis of the refurbishment project's components (walls, windows, roof, floors, volumetric planning and engineering services, etc) and select the most efficient versions. After this, the received compatible and rational components of a refurbishment are joined into the projects. Having performed a multiple criteria analysis of the projects in this way, one can select the most efficient projects. Strengths and weaknesses of the investigated projects are also given in an analysis. Facts as to why and to what degree one version is better than another are also established. All this is done by basing oneself on conceptual and quantitative information that was collected.

Module base provides support to the user so that he/she can develop different alternatives that are based on combinations of the user's requirements. The developed measures are checked for consistency of measure combinations as well as for interference with deterioration, obsolescence and other related actions. Each alternative shows different levels of improvements to the building's quality and all have variations in the projected cost. A module base allows the BR-DSS's user to select the most suitable refurbishment alternatives by comparing the measures that promote the greatest energy savings and increase a building's quality within the budget constraints of the building's inhabitants.

The following models of a model-base aim at performing the functions of:

- A model for developing the alternative variants of a building's enclosures,

- A model for determining the initial weight of the criteria (with the use of expert methods),

- A model for establishing the criteria weight,

- A model for the multi-variant design of a building refurbishment,

- A model for multiple criteria analysis and for setting the priorities,

- A model for the determination of a project's utility degree and market value,

- A model for providing recommendations.

Based on the above models, the BR-DSS can make up to 100,000 building refurbishment alternative versions, perform their multiple criteria analysis, determine the utility degree and select the most beneficial variant without human interference (Table 2).

The BR-DSS presents information about the building's diagnosis and questionnaires as well as different scenarios for the building's refurbishment. The report contains information about the estimation of potential energy savings and improvement of quality of building: thermal insulation of building envelope (walls, roof, windows); the cost of refurbishment work; comparison with the corresponding qualitative indices of an typical building built in the same period; potential impact of refurbishment to increase the quality of building to the level of present standard. This is useful software for selecting the best possible scenarios.

Table 2. Selection of the most efficient alternatives of the building refurbishment

\begin{tabular}{|c|c|c|c|c|}
\hline \multirow{2}{*}{$\begin{array}{l}\text { THE KNOWLEDGE BASE OF } \\
\text { THERMAL RENOVATION OF } \\
\text { WALLS }\end{array}$} & \multicolumn{4}{|c|}{ Selection of the most efficient alternatives of the building refurbishment } \\
\hline & Priority & Numeration & Total weight & Total utility degree \\
\hline \multirow{2}{*}{$\begin{array}{l}\text { THE KNOWLEDGE BASE OF } \\
\text { THERMAL RENOVATION OF } \\
\text { ROOF }\end{array}$} & 1 & 1 & 61,50 & 100,0 \\
\hline & 2 & 1729 & 61,42 & 99,87 \\
\hline \multirow{3}{*}{$\begin{array}{l}\text { THE KNOWLEDGE BASE OF } \\
\text { THERMAL RENOVAIION OF } \\
\text { BASEMENT }\end{array}$} & 3 & 3457 & 61,27 & 99,63 \\
\hline & 4 & 193 & 61,13 & 99,40 \\
\hline & 5 & 1921 & 61,05 & 99,27 \\
\hline \multirow{2}{*}{$\begin{array}{l}\text { THE KNOWLEDGE BASE OF } \\
\text { THERMAL RENOVATION OF } \\
\text { WINDOWS }\end{array}$} & 6 & 3713 & 60,90 & 99,02 \\
\hline & 7 & 577 & 60,48 & 98,36 \\
\hline \multirow{4}{*}{$\begin{array}{l}\text { THREE BEST VERSIONS OF } \\
\text { SOLUTIINS UNDER } \\
\text { CONSIDERATION }\end{array}$} & 8 & 2305 & 60,41 & 98,23 \\
\hline & 9 & 65 & 60,33 & 98,10 \\
\hline & 10 & 4033 & 60,26 & 97,98 \\
\hline & 11 & 1793 & 60,25 & 97,97 \\
\hline
\end{tabular}




\section{Conclusion}

The presented BR-DSS for a building's refurbishment enables one to form up to 100,000 alternative versions. This system allows one to determine the strongest and weakest points of each building's refurbishment project and its constituent parts. Calculations are made to find out by what degree one version is better than another and the reasons why this is so are disclosed. Landmarks are set for increasing the efficiency of a project's versions. All this is done argumentatively by basing oneself on the criteria under investigation, as well as on their values and weights.

\section{References}

1. Balaras, C. A. TOBUS - A European method and software for office building refurbishment. Energy and buildings, Vol 34, Issue 2, February 2002, p. 111-112.

2. Becker, R. and Paciuk, M. Energy and buildings. Interrelated effects of cooling strategies and building features on energy performance of office buildings. Energy and buildings, Vol 34, Issue 1, Jan 2002, p. 25-31.

3. Bluyssen, P. M. EPIQR and IEQ: indoor environment quality in European apartment buildings. Energy and buildings, Vol 31, Issue 2, Febr 2000, p. 103-110.

4. Bojic, M.; Yik, F.; Sat, P. Energy performance of windows in high-rise residential buildings in Hong Kong. Energy and buildings, Vol 34, Issue 1, Jan 2002, p. 71-82.

5. Brandt, E.; Rasmussen, M. H. Assessment of building conditions. Energy and buildings, Vol 34, Issue 2, Febr 2002, p. 121-125.

6. Butala, V.; Novak, P. Energy consumption and potential energy savings in old school buildings. Energy and buildings, Vol 29, Issue 3, Jan 1999, p. 241-246.

7. Caccavelli, D.; Genre, J. L Diagnosis of the degradation state of building and cost evaluation of induced refurbishment works. Energy and buildings, Vol 31, Issue 2, Febr 2000, p. 159-165.

8. Caccavelli, D.; Gugerli, H. TOBUS - a European diagnosis and decision-making tool for office building upgrading. Energy and buildings, Vol 34, Issue 2, Febr 2002, p. $113-119$.

9. Chow, T. T.; Zhang, G. Q.; Lin, Z.; Song, C. L. Global optimization of absorption chiller system by genetic algorithm and neural network. Energy and buildings, Vol 34, Issue 1, Jan 2002, p. 103-109.

10. Crawley, D. B.; Lawrie, L. K.; Winkelmann, F.C.; Buhl, W. F.; Huang, Y. J.; Pedersen, C. O.; Strand, R. K.; Liesen, R. J.; Fisher, D. E.; Witte, M. J.; Glazer, J. EnergyPlus: creating a new-generation building energy simulation program. Energy and buildings, Vol 33, Issue 4, April 2001, p. 319-331.

11. Dave, B. et al. Case based design in architecture in: Gero, Sudweeks (Eds.), Artificial intelligence in design, Kluwer Academic Publishers, Dordrecht, Hingham, MA, 1994, p. 145.

12. Dhakal, S.; Hanaki, K. Improvement of urban thermal environment by managing heat discharge sources and sur- face modification in Tokyo. Energy and buildings, Vol 34, Issue 1, Jan 2002, p. 13-23.

13. Dorer, V:; Weber, A. Air, contaminant and heat transport models: integration and application. Energy and buildings, Vol 30, Issue 1, Apr 1999, p. 97-104.

14. Flourentzos, F.; Droutsa, K.; Wittchen, K. B. EPIQR software. Energy and buildings, Vol 31, Issue 2, Febr 2000, p. $129-136$

15. Genre, J. L.; Flourentzos, F.; Stockli, T. Building refurbishment: habitat upgrading. Energy and buildings, Vol 31, Issue 2, Febr 2000, p. 155-157.

16. Goodacre, C.; Sharples, S.; Smith, Peter. Integrating energy efficiency with the social agenda in sustainability. Energy and buildings, Vol 34, Issue 1, Jan 2002, p. 5361.

17. da Graça, G. C.; Chen, Q.; Glicksman, L. R.; Norford; L. $\mathrm{K}$. Simulation of wind-driven ventilative cooling systems for an apartment building in Beijing and Shanghai. Energy and buildings, Vol 34, Issue 1, Jan 2002, p. 1-11.

18. Imanari, T.; Omori, T.; Bogaki, K. Thermal comfort and energy consumption of the radiant ceiling panel system. Comparison with the conventional all-air system. Energy and buildings, Vol 30, Issue 2, June 1999, p. 167-175.

19. Jaggs, M.; Palmer, J. Energy performance indoor environmental quality retrofit - a European diagnosis and decision making method for building refurbishment. Energy and buildings, Vol 31, Issue 2, Febr 2000, p. 97-101.

20. Kolokotsa, D.; Tsiavos, D.; Stavrakakis, G. S.; Kalaitzakis, K.; Antonidakis. E. Advanced fuzzy logic controllers design and evaluation for buildings' occupants thermal-visual comfort and indoor air quality satisfaction. Energy and buildings, Vol 33, Issue 6, July 2001, p. 531-543.

21. Kukadia, V.; Palmer, John. The effect of external atmospheric pollution on indoor air quality: A pilot study. Energy and buildings, Vol 27, Issue 3, June 1998, p. 223230.

22. Kusuda, T. Building environment simulation before desk top computers in the USA through a personal memory. Energy and buildings, Vol 33, Issue 4, Apr 2001, p. 291302.

23. Mazouz, S.; Zerouala, M. S. The integration of environmental variables in the process of architectural design. The contribution of expert systems. Energy and buildings, Vol 33, Issue 7, Sept 2001, p. 699-710.

24. Oxford dictionary of computing. Oxford University Press. 1996. 394 p.

25. Peuportier, B. L. P. Life cycle assessment applied to the comparative evaluation of single family houses in the French context. Energy and buildings, Vol 33, Issue 5, May 2001, p. 443-450.

26. Rey, F. J.; Velasco, E. Experimental study of indoor air quality, energy saving and analysis of ventilation norms in climatised areas. Energy and buildings, Vol 33, Issue 1, Nov 2000, p. 57-67.

27. Roulet, C. A. Indoor environment quality in buildings and its impact on outdoor environment. Energy and buildings, Vol 33, Issue 3, Febr 2001, p. 183-191.

28. Saporito, A.; Day, A. R.; Karayiannis, T. G.; Parand, F. Multi-parameter building thermal analysis using the lattice 
method for global optimisation. Energy and buildings, Vol 33, Issue 3, Febr 2001, p. 267-274.

29. Sodec, F. Economic viability of cooling ceiling systems. Energy and buildings, Vol 30, Issue 2, June 1999, p. 195201.

30. Zmeureanu, R.; Fazio, P.; DePani, S.; Calla, R. Development of an energy rating system for existing houses. Energy and buildings, Vol 29, Issue 2, 1999, p. 107-119.

[1] "My facilities.com-comfort calculator", Available: http:// www.automationcollege.com/myfacilities/tools/ comfortcalculator.asp (Accessed: 2002, January)

[2] "My facilities.com-lighting calculator", Available: http:// www.automationcollege.com/myfacilities/tools/ lightingcalculator.asp (Accessed: 2002, January)

[3] "My facilities.com-ventilation calculator", Available: http://www.automationcollege.com/myfacilities/tools/ ventilationcal.asp (Accessed: 2002, January)

[4] "Realtor.com - home inprovement calculator", Available: http://www.homestore.com/home improvement/planning/ calculators $/$ default.asp?gate $=$ realtor $\&$ source $=1$ xxxotzzz 9 (Accessed: 2001, October)

[5] E. Zavadskas, F. Peldschus, A. Kaklauskas. Multiple criteria evaluation of projects in construction / Institute of technological and economic development (ITED), Vilnius Technical University. Vilnius: Technika, 1994. 226 p.

[6] Kaklauskas, A.; Zavadskas, E. Web-based decision support. Vilnius: Technika, 2002. 292 p. (in Lithuanian).

[7] Zavadskas, E.; Kaklauskas, A.; Ambrasas, G.; Jonaitis, V. The selection of rational refurbishment version of dwelling houses by making use of the multicriteria system. In: Building an heritage for the future. Proceedings of the XXV IAHS World Building Congress. Lisbon, Portugal, 29 June-3 July 1998, p. 692-701.
[8] Zavadskas, E.; Kaklauskas, A.; Turskis, Z.; Ambrasas, G. Refurbishment decision support system. In: International conference "Information technologies for education, science and business". Minsk, Belorus, 1999, p. 22-26.

[9] http://www.eere.energy.gov/buildings/tools_directory/ subject.html

[10] http://www.eere.energy.gov/buildings/tools directory/software/blast.htm

[11] http://www.eere.energy.gov/buildings/tools directory/software/doe- $2 . \mathrm{htm}$

[12] http://www.eere.energy.gov/buildings/tools_directory/software/ea-quip.htm

[13] http://www.eere.energy.gov/buildings/tools_directory/software/ezsim.htm

[14] http://www.eere.energy.gov/buildings/tools_directory/software/ezdoe.htm

[15] http://www.eere.energy.gov/buildings/tools directory/software/feds.htm

[16] http://www.eere.energy.gov/buildings/tools_directory/software/serires.htm

[17] http://www.eere.energy.gov/buildings/tools directory/software/tsbi3.htm

[18] http://www.eere.energy.gov/buildings/tools directory/software/visualdoe.htm

[19] http://www.eere.energy.gov/buildings/tools_directory/database/page. $\mathrm{cfm}$ ?Cat $=$ CodesStds\&Status $=$ Yes \&Menu= $5 \&$ Desc $=$ Codes + and + Standards

[20] http://www.eere.energy.gov/buildings/tools directory/ subject.html

[21] http://www.eere.energy.gov/buildings/tools directory/ subject.html 